\section{Separação, Colonização \\ e Contestạ̧ão: Por Uma Busca de Uma Historiografia Africanista}

\section{Resumo}

No presente artigo, vamos desenvolver algumas das etapas do processo que levaram à divisão do continente africano para uma estruturação do colonialismo e dos processos de contestação de suas lideranças, visando compreender de que modo autores como Joseph Ki-zerbo, Terence Ranger, Vicent Khapoya, entre outros, elaboraram um material historiográfico objetivando as respectivas respostas à sua colonização. Os processos de resistência ao colonialismo na época contemporânea foram atuações políticas encabeçadas por Samory Touré, Omar Tall e Mohamed Ahmad. Vistos como processos de resistência, essas análises podem incentivar novas pesquisas as quais retomem e aprofundem ainda mais temáticas importantes na desconstrução das ideias de uma (suposta) aceitação e da passividade do negro-africano.

Palavras-chaves: contestação, estudos africanos, História da África, colonialismo.

\section{Abstract}

In this article we will develop some of the stages of the process that led to the division of the African continent, aiming at the formation of the colonialism basis and the processes' development of leaderships, whose resistances show us how to understand authors such as Joseph Ki-Zerbo, Terence Ranger, Vicent Khapoya, among others. They produced historiographical material to account for the respective responses to colonization within the African continent. The processes of resistance to colonialism in the contemporary era were political actions led by Samory Touré, Omar Tall and Mohamed Ahmad. Seen as processes of resistance these analyzes may encourage new research which will take up and further deepen these important themes in deconstructing the ideas of a supposed acceptance and passivity of black Africans.

Keywords: contestation, African studies, African History, colonialism.
Gustavo de Andrade Durão

Doutor em História

Comparada pela UFRJ, Pósdoutorado pelo Programa de Pós-Graduação da UFRRJ. Atualmente é professor da Universidade Estadual do Piauí - UESPI (Campus São Raimundo Nonato). Coordenador do GPHENT (Grupo de Pesquisa em História, Educação e Narrativas Transnacionais) E-mail: gdurao @outlook.com 


\section{Introdução}

As análises da historiografia africana têm surgido para demonstrar como alguns dos seus mitos foram construídos meticulosamente ao longo de alguns anos. Ao estudar sobre a História da África estamos inadvertidamente captando somente nossa percepção acerca de uma narrativa fundada nos centros acadêmicos europeus. Os pesquisadores e professores voltados para os estudos africanos precisaram fazer uma autocrítica em relação a algumas ideias, principalmente quando se aborda o contato colonial nos séculos XIX e XX, bem como as consequências dessas abordagens.

Nossa perspectiva inicial é aceitar o triste pressuposto de que a História dos povos africanos foi contada inicialmente pelos colonizadores, cujo objetivo principal era cumprir uma agenda política republicana. Essa constituição de uma "memória ambígua" fez com que as interpretacões sobre a África estivessem sempre carregadas do estigma da tutela da metrópole sobre as suas colônias. "Fratura colonial" presente em uma historiografia responsável por negar e marginalizar as narrativas das populações nativas (VERGÈS, 2006, p. 73).

A (auto) crítica por parte da historiografia francesa atuou na percepção da história da escravidão como algo que pertencia às conquistas europeias e não à sujeição dos indivíduos. O que se tornou mais problemático nas abordagens dos historiadores franceses foi terem se deparado com a continuidade de uma perspectiva etnocêntrica repetida nas interpretações sobre o colonialismo. Dito de outra maneira, foi necessário perceber a condição humana presente na coleta de dados sobre a escravidão, a pós-escravidão e o colonialismo (VERGĖS, 2006, p. 76).

Acreditou-se ter auxiliado na percepção do quanto o continente africano fora negligenciado das análises mais ligadas às explicações das histórias, tradições, línguas e cultura em geral. Nesse sentido, compreender que a África até 1880 não estava fechada ao mundo externo, já representa um grande avanço, aliado à percepção da grande pluralidade dos seus países, imprescindivel para o aprimoramento de algumas pesquisas na área. Os processos coloniais foram particularmente violentos, mas não é possível descartar as lutas no âmbito da contestação aos contatos entre diferentes civilizações (M'BOKOLO, 2011, p. 329).

Uma grande contribuição foi a abordagem do historiador malinês Joseph Ki-Zerbo, cuja obra, além de lutar contra os estigmas do preconceito e do racismo de toda ordem, também combateu uma conjuntura neocolonial extremamente prejudicial para os estudos da História da África (KI-ZERBO, 2009, p. 14). Destaca-se, ainda, sua percepção de História na qual os indivíduos se pautam nessa ciência humana buscando determinada certeza para encontrar, "reconstruir e explicar o passado do homem (KI-ZERBO, 2009, p. 34)."

Defende-se, assim, a perspectiva historiográfica de Ki-Zerbo quando aponta o ciclo de sentimentos de ódio, o qual podemos desencadear estudando o tráfico atlântico, a escravidão e colonialismo, contudo, isso aumenta ainda mais nossa responsabilidade de dar o devido valor às análises dos fatos minimizados por tanto tempo pelos historiadores europeus (KI-ZERBO, 2009, p. 35).

É preciso, portanto, arrazoar o quanto uma historiografia colonialista representou os líderes africanos contrários ao contato colonial como seres irracionais contrários ao avanço da civilização e ao progresso. Por isso, abordaremos um pouco do contexto colonial para buscar compreender de que modo a resposta ao processo de dominação abrange aspectos sócio-político-econômicos fundamentais às dinâmicas de poder, constituindo elementos que valorizem a reflexão dos estudos africanos no Brasil. Contudo, consideraremos primeiramente alguns aspectos dessa aproximação colonial do século XIX e XX.

\section{Repensando a Historiografia da Partilha e da Colonização}

Nosso objetivo principal aqui é resgatar um pouco do que foi produzido sobre a partilha e 
o colonialismo, levando em consideração o caráter ensaísta do texto, bem como seu espaço. O crescimento dos estudos africanos no Brasil encontrou dificuldades nas traduções e na falta de recursos para o aprofundamento das interpretações. Devido às aproximações das relações África-Brasil, as fontes em língua portuguesa foram supervalorizadas, abrindo um espaço restrito para análises mais heterogêneas.

Por meio de amplas lutas na sociedade brasileira, desde 2003 houve um forte incentivo para o ensino da disciplina de História da África e da cultura afro-brasileira a partir da lei 10.639, do mesmo ano. Assim, era necessário capacitar professores e realizar um balanço de nossas raízes africanas levando-se em conta séculos de escravização e a grande porcentagem da população brasileira ser negra. Graças aos incentivos aliando sociedade civil e programas do governo houve uma possibilidade de revigorar os estudos africanos e estabelecer o cânone dentro no campo educacional brasileiro.

Na definição clássica da História da Revolução Industrial ocorrida em vários países da Europa, conferiu-se à Inglaterra um papel de protagonismo na história econômica. Com a emancipação das 13 colônias, Lorde Chamberlain visava investir na Índia e na África alegando o projeto da nova política colonial britânica, conferindo novas matérias-primas para fazer circular a economia inglesa e, assim, também propiciar o crescimento da atividade náutica da Inglaterra (FERRO, 2017, p. 55).

De maneira geral, em fins do século XIX, o racismo científico ratificou às pesquisas os preceitos ideológicos para a dominação. Desse modo, o africano era associado, ainda, ao atraso ou ao fracasso civilizacional. A ciência histórica (bem como a antropologia) permanecia representada pela escrita, desprezando a oralidade africana, fonte fundamental de recorte e manutenção das tradições. Muito embora a definição de povos sem História de Hegel já tivesse caído por terra, somente a partir de 1960 as justificativas raciais foram descartadas totalmente pela comunidade acadêmica (CURTIN, 1982, p. 41).
O que ocasionou e legitimou a aproximação predatória dos países europeus em relação aos africanos foi justamente essa defasagem tecnológica ocorrida em decorrência das revoluções industriais. Inconteste foi o desenvolvimento das ferrovias, da telegrafia, das máquinas a vapor e dos meios de transportes em geral, o que para a Europa representou avanços em termos de desenvolvimento, os quais colocavam quase a totalidade do continente africano em desvantagem em termos de tecnologia (RANGER, 2011, p. 51).

A Conferência realizada em Berlim de 15 de novembro de 1884 a 26 de novembro de 1885 , traz em seu cerne diversas contradições. Mais uma vez havia uma justificativa humanitária (e mesmo civilizatória), não obstante o peso dos motivos econômicos como estopim para os debates sobre a exploração do continente. Diferentemente do que versam os livros didáticos, a Conferência de Berlim não queria partilhar a África, mas configurou-se em uma reunião em âmbito internacional para gerenciar as maneiras de levar os "avanços tecnológicos" aos territórios africanos e garantir o fim da escravidão no continente.

\begin{abstract}
A conferência, que inicialmente, não tinha por objetivo a partilha da África, terminou por distribuir os territórios e aprovar as resoluções sobre a livre navegação no Níger, no Benue e seus afluentes, e ainda por estabelecer as 'regras a serem observadas no futuro em matéria de ocupacão de territórios nas costas africanas.' (UZOIGWE, 2011, p. 33)
\end{abstract}

A clássica representação da iconografia da Conferência com os líderes ao redor de uma mesa de debates leva a pensar o papel de protagonismo dos políticos e poderosos de países como Alemanha, França, Inglaterra e Bélgica nos projetos futuros para a África. Essa concepção esteve tão arraigada ao pensamento intelectual que não temos a noção de "povo africano", ou de etnias específicas das regiões africanas. 
As ciências da época (com ênfase para a Geografia) pensavam uma melhor maneira de levar a "civilização" para os povos vistos como atrasados do continente. A liderança da Bélgica nesse processo não pode ser ignorada, visto que o Rei Leopoldo II tinha interesse na colonização "moderna" de uma parte em especial do continente: o Congo.

\begin{abstract}
Em setembro de 1876, na linha da ideologia humanitária, o mecenas reuniu em seu palácio em Bruxelas uma conferência internacional de Geografia. $\bigcirc$ objetivo era "abrir à civilização a única parte de nosso globo em que ela não havia ainda penetrado... conferenciar para acertar o passo, combinar esforços, tirar partido de todos os recursos, de evitar a duplicação de trabalhos'. (BRUNSCHWIG, 2006, p. 30)
\end{abstract}

A historiografia da Conferência de Berlim ainda tem algumas lacunas, e como aponta o historiador francês Henri Brunschwig, o monarca belga investiu nas ciências para legitimar a retomada dos territórios africanos no Congo. Nesse sentido, a História das Relações Internacionais não pontuou devidamente os temas específicos da contestação à aproximação europeia nessa virada de século, muito embora saibamos o quanto o continente estava fragilizado economicamente pela queda do comércio atlântico de escravizados.

Desde 1880, devido ao boom da industrialização, fez-se necessário implementar um sistema de dominação cuja expansão se daria nos territórios de além-mar. "Filha da política industrial", a colonização seria o novo pilar econômico para por meio da "liberdade de troca" se alcançar mais lucro. O caso da França foi interessante, pois com a perda para a Prússia, em 1871, e a consequente perda da Alsácia-Lorena, a Terceira República tratou uma compensação por meio da anexação dos territórios de além-mar (FERRO, 2017, p. 56).

Ainda sobre a "Partilha", é interessante notar como as disputas internas contribuíram para que a chegada do europeu (estrangeiro) fosse vista como um fator de auxílio para a resolução das rivalidades internas. Aliado a isso, outro fator é apontado por Godfrey Uzoigwe (2011, p. 45):

O fator mais decisivo foi, evidentemente, a esmagadora superioridade logística e militar da Europa. Enquanto esta empregava exércitos profissionais bem treinados, poucos Estados africanos possuíam exércitos permanentes e menos ainda dispunham de tropas profissionais. $\mathrm{Na}$ sua maior parte, faziam recrutamentos e mobilizações ad hoc para as necessidades de ataque e defesa.

Desde então, (início do século XX), as grandes potências europeias já tinham ganhado a maioria dos combates dentro do território africano. Destarte, a tecnologia europeia venceu as batalhas pela sua instalação no continente, sobretudo, se levarmos em conta o poder de fogo da metralhadora Maxim e seu alto poder de destruição. Contudo, é necessário considerar que a permanência europeia no continente encontraria grandes obstáculos, como veremos adiante (UZOIGWE, 2011, p. 49).

Como bem aponta Edward Said, o discurso colonial já reproduzia por meio da literatura toda uma dinâmica de inferiorização, como se o continente em si fosse algo perdido, que nunca pudesse ser "regenerado". A obra em que mais se verificava isso era, sem sombra de dúvidas, o "Coração das Trevas", de Joseph Conrad, de 1902 (SAID, 2005, p. 58). A literatura colonial foi analisada a posteriorie a figura de Alain Quatermain, "As minas do Rei Salomão" (1885), ilustrou bem o caminho aventureiro e civilizatório no qual os europeus estavam destinados a trilhar. Foi preciso lembrar o já citado "Coração das Trevas", surgido quase na mesma época e influenciado pelas expedições no Congo (HOCHSCHILD, 1997, p. 12).

De modo análogo, Said realiza uma interessante análise sobre o romance de Edgar Rice Burroughs "Tarzan - o rei dos macacos" (1912), enfatizando a importante relação entre o fortalecimento da literatura vitoriana e as crescentes 
expedições no continente africano. Ou seja, o colonizado e o africano eram liderados por essa figura mitológica que, apesar de ser selvagem, tinha sua origem europeia positivada reforçando as tendências evolucionistas do século XIX, em detrimento dos autóctones do continente (SAID, 2003, p.147-8).

Não será aprofundado aqui, mas é interessante lembrar o quanto essa literatura de conquista oitocentista iria impactar as gerações futuras dos nativos, dando legitimidade a uma escrita voltada em responder os preconceitos, racismos e a exclusão da segregação colonial desse pretérito de violência e negação. Essa geração posterior foi formada por Aimé Césaire, Salman Rushdie e Chinua Achebe, só para citar alguns exemplos de escritores do que se convencionou chamar de literatura pós-colonial (SAID, 2005, p. 64).

O colonialismo aparece como uma chave de interpretação importante, visto que teve claramente a função de separar os grupos nativos para controlar não só os corpos, mas as mentalidades. De modo mais enfático, é possível dizer que "O colonialismo pôs fim a tudo isso e privou assim os Estados da África da possibilidade de adquirir experiência no domínio da diplomacia e das relações internacionais" (BOAHEN, 2009, p. 927).

A necessidade comercial europeia veio acompanhada de uma justificativa ideológica e o Norte da África e a Costa Ocidental do continente foram os espaços mais afetados por essa penetração político-econômica europeia:

A nova expansão islâmica associada ao desdobramento das redes comerciais que atravessavam o Saara, conectando-se aos postos de troca no oceano Atlântico, e ao crescimento do comércio de armas alteraram a paisagem política e militar da região, possibilitando reações de maior envergadura dos africanos à presença europeia. (BITTENCOURT, 2003, p. 8)

As colônias africanas foram logo percebidas como uma maneira não só de enriquecimento, mas de se atingir um status privilegiado diante das mudanças na geopolítica mundial (KHAPOYA, 2015, p. 147). O período de virada do século XIX para o XX foi de fundamental importância, visto ter situado definitivamente o continente na rota do capitalismo europeu e demonstrado as complexas estruturas político-sociais concernentes ao continente. Para além do contexto econômico pode-se perceber, sobretudo, em parte da África Ocidental, um contexto de lutas, conquistas e delimitações cujas bases permitem compreender as resistências ao contato colonial (MACEDO, 2015, p. 126). Contudo, antes de adentrar nas movimentações dos líderes africanos em oposição à colonização, é necessário um breve apanhado sobre o contato das potências europeias na África.

\section{Colonialismo e Dominação}

A própria relevância do colonialismo diante de sua contestação é ainda difícil de ser mensurada, visto que a História só contava as narrativas das vitórias quando as populações inteiras eram subjugadas. As mobilizações contrárias ao contato europeu acabaram sendo ignoradas, visto que poderia haver uma "demonização" dos seus líderes e uma generalização da qual as interpretações seriam sempre ligadas à aceitação de modo pacífico dessa empreitada colonial (RANGER, 2011, p. 52).

Das ruinas do Império Otomano surgem importantes colônias que serviram para o povoamento, como a Argélia, Tunísia e Egito, gerando certa tranquilidade por parte dos administradores europeus na divisão deste vasto território. Diante disso, a colonização foi se fortalecendo por meio dos tratados mútuos entre as potências colonizadoras, amparadas pelo discurso colonial do qual "civilizar" era levar o progresso e o avanço para as regiões ainda fechadas no continente (FERRO, 2017, p. 72-3).

A etnologia e a antropologia ratificaram essa noção de que havia seres humanos menos capazes de se civilizar. A preexistência dos estados nacionais europeus pode ser uma justificativa para iniciar essa interferência tão hostil nos territórios africanos e asiáticos. Além dos 
fatores políticos e econômicos, o continente africano passou por uma grande interferência dos Estados europeus, sobretudo, quando os governantes tinham o ideal de superioridade racial nutrindo suas ações.

Seria necessário o surgimento da obra de Frantz Fanon nas décadas de 1950-60 para desmascarar a obra do racismo científico (substituído pelo racismo culturalista), e demonstrar o quão pernicioso era essa métrica de dominação. O colonialismo, bem como o racismo, sempre encontraria uma nova forma de divisão e de exclusão, em que a violência do colonizado poderia ser a resposta que poria fim a décadas de conflitos (BOUAMAMA, 2017, p. 40).

Durante as primeiras décadas do século $X X$ eram recorrentes as exposições coloniais demonstrando não somente a força da "civilização" europeia sob esses povos, mas de que modo as populações africanas ainda viviam no "reino da natureza". Esses verdadeiros "zoológicos humanos" enfatizavam o contato com a realidade dos negros na África demonstrando a força da "civilização" e um projeto de dominacão travestido de ajuda humanitária (MACEDO, 2015, p. 146; BLAKE, 2002, p. 38).

Em 1931, a França realizava a Exposição Colonial em que eram apresentados os objetos e os "espécimes" de povos africanos, por meio da demonstração do exotismo dos sujeitos e o reforço de parte dos preconceitos relacionados aos grupos do que seria na época a África Ocidental Francesa. Essa exposição coincidiu com o apogeu do Império francês demonstrando para onde iria grande parte do investimento europeu na sujeição desses grupos humanos autóctones. Em oposição a essa exposição, a Verité sur les colonies (Verdade sobre as Colônias) foi outra exposição ocorrida para demonstrar uma resistência a essa visão hegemônica da dominação e, influenciada pelo marxismo, pôs em xeque a justificativa econômica para que esta ocorresse (BLAKE, 2002, p. 38-40).

Durante muito tempo, civilização e colonização foram conceitos complementares e certamente a ideia de progresso dependeria do quanto uma potência pudesse se sobrepor à outra. A colonização dos séculos XIX e XX teve a especificidade de não manter a designação colonizado e colonizador; pois havia o colono, um híbrido no meio dessa equação. Então surge um terceiro tipo de indivíduo, que é o colono. Esse terceiro personagem luta com unhas e dentes pela manutenção do status da metrópole, que luta arduamente contra o colonizado (autóctone). Ele se desvencilhou dos valores morais para lutar pela causa da manutenção do território, tornando mais complexa a disputa entre os anseios dos nativos e dos colonizadores (FERRO, 2016, p. 13).

Aliado a isso, as ideologias do século XIX sobre o pan-africanismo, por mais contraditórias que fossem, já demonstravam uma crítica ao modus operandi do colonialismo. Evidente que não é possível esquecer o papel de violência do contato colonial, sobretudo, na África Ocidental Francesa, até porque os mecanismos mais utilizados pelos administradores coloniais eram as armas e a coerção dos indivíduos (ILIFFE, 2009, p. 394-5).

O estudo das resistências africanas põe em xeque essa narrativa única e eurocentrada, acentuando maniqueísmos como o existente entre o conceito de tradição e modernidade, essenciais na compreensão das relações entre Europa e África na contemporaneidade. Assim, alguns chefes de grupos influentes podem ter aceitado a penetração dos europeus como promessa de modernização real do continente (RANGER, 2008, p. 254).

O mito de exclusão do continente africano se faz mais evidente quando trabalhamos do comércio triangular de escravizados, cujo declínio gerou um forte impacto no continente africano, possibilitando o enfraquecimento das relações político-sociais desses territórios em relação ao resto do mundo. Esse comércio significava a exportação dos cativos oriundos fundamentalmente do Congo e de Luanda, visando reforçar os postos de trabalho escravo nas Américas. Desse modo, África, Europa e Américas participavam de uma intensa troca de produtos agrícolas das colônias, escravos 
e de certa quantidade de produtos manufaturados enviados da Europa para o continente africano (FERRO, 2016, p. 31).

Em grande parte de sua obra, Victor $G$. Kiernan (Imperialismo e suas contradições, 1995) ilustra como os africanos foram alistados nos exércitos coloniais, levando em consideracão uma perspectiva centrada na narrativa dos colonizadores. Contudo, o autor deixa claro - quanto havia uma retórica para que esses colonizados utilizassem o serviço militar para atingir a cidadania, capaz de alçá-los em condição de igualdade com os europeus.

Em 1914, o deputado senegalês Blaise Diagne consegue por meio de uma interpelação junto ao parlamento pedir com que os africanos pudessem se alistar no exército francês, começando legalmente o alistamento dos súditos coloniais. $O$ exemplo dos atiradores senegaleses é sintomático, visto que tiveram uma grande participação nas guerras coloniais, sobretudo, nas batalhas pela Argélia (QUADRAT, ROLEMBERG, 2011, p. 28). Apesar dos discursos preconceituosos sobre o negro, era comum a defesa dos atributos destes, pois nos documentos oficiais a defesa do recrutamento dos súditos africanos era realizada exaltando, inclusive, a defesa do território e levando-os a pensar que estavam trabalhando para pacificar seus países (KIERGAN, 1995, p. 84-6).

Essa historiografia clássica exaltava os males da intervenção europeia no tocante a divisão dos grupos étnicos, em que muitas vezes as rivalidades eram acirradas. Talvez a violência tenha surgido dessa resposta ao colonizador e, com isso, foi possivel observar, por exemplo, o quanto os argelinos esqueceram todas as "melhorias" francesas no período da descolonização argelina (KIERNAN, 1995, p. 86).

\section{Contestação e Mobilização no Norte da África}

Dentro dessas breves páginas, acabaremos por falar sobre as resistências de modo mais pontual, levando em consideração algumas mudanças ocorridas entre o século XIX e XX. Muito utilizado pela historiografia sobre a escravidão, o conceito de resistência atua em uma perspectiva de compreensão da não vitimização dos sujeitos históricos, desfazendo a perspectiva de uma aceitação das atividades escravistas e de colonização (THORNTON, 2004, p. 355-6).

A resistência aparece como tentativa de deslegitimar a noção dos vencidos, cuja perspectiva geralmente permeia as interpretações sobre a História da África e de seus sujeitos. No caso brasileiro, a noção de resistência só aparece nos processos de escravização dos nativos e, no continente africano, ela toma forma quando na virada do século XVIII para o XIX os europeus conseguem de forma mais eficaz adentrar nos territórios que seriam as novas zonas coloniais (FERRO, 2008, p. 225).

Compreende-se o quanto foi mais difícil penetrar no continente africano do que nos espaços coloniais americanos, mas isso não invalida as comparações entre os dois processos. No caso africano, vale lembrar que o contato com a Europa era secular, desfazendo-se o mito de um continente fechado ao contato exterior. Evidentemente, as relações dos países africanos com os europeus só vêm ganhando mais destaque de pouco tempo até agora muito em parte por conta do revisionismo historiográfico.

Logo, não foi a falta de interesse pela África que freou o avanço de diversos colonizadores dos séculos XV a XIX, e tampouco suas opções comerciais, mas de fato a sua capacidade de se defender - caso contrário os europeus teriam dominado territórios inteiros [...] (FERRO, 2008, p. 226). Nesse sentido, a compreensão da resistência no continente fica ainda mais em evidência, tendo em conta o quanto há certos silenciamentos acerca de narrativas como a da rainha do Kongo-Angola, Nzinga Mbandi, em meados do século XVI. Dito de maneira geral, o caso de rainha Nzinga é exemplar, pois trata da penetração católica no reino do Kongo e como se deram os processos de assimilação e entrada no continente (FERRO, 2008, p. 226).

As resistências ocorridas no território do Congo se tornaram forma de luta contra o 
ostensivo mecanismo de dominação perpetrado por Leopold II da Bélgica, em 1884. Como apontado por Bittencourt (2003, p.11): "A fuga para o interior e as rebeliões de pequenas comunidades ou até mesmo individuais foram as estratégias possiveis contra o selvagem mecanismo de controle criado por Leopold II e mantido durante alguns anos pelo governo belga." A extrema violência disseminada pelos europeus gerou decapitações, mutilações e assassinatos, tudo em nome do ideal exploratório colonizador.

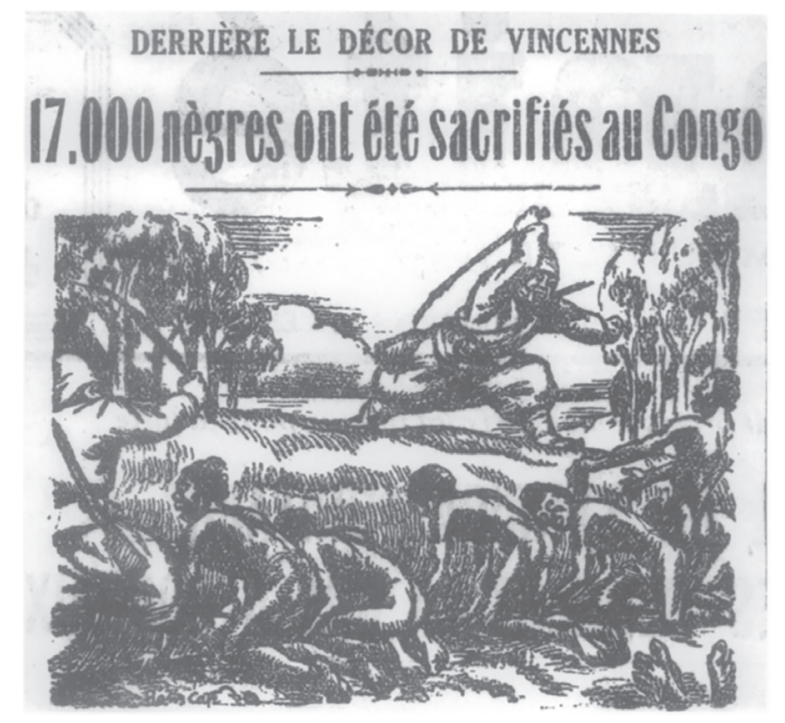

Figura 1 - Contestação dos massacres no Congo (BLAKE, J.. The truth About Colonies, 1937: Art Indigène in Service of Revolution. Oxford Art Journal, vol. 25, n.1, 2002, p. 47.

Fonte: A autora reproduz a representação encontrada no Arquivo d'autre-mer de Aix-en-Provence.)

Como dito anteriormente, em geral o conceito de resistência é empregado para se compreender não somente a oposição à escravidão nas Américas, mas também, para se entender de que modo os escravizados mantinham suas tradições culturais, ou seja, traços de sua ancestralidade. À isso a antropologia chamou de resistência cultural.

Se levarmos em consideração as estruturas sócio-político-econômicas na África da virada do século XIX ao XX, veremos diversos fatores bastante complexos para o estudo das variadas sociedades da África Negra. No que se refere aos contatos da França e da Inglaterra com certas partes do continente, percebe-se o quanto os fatores religiosos, por exemplo, culminaram na participação de lideranças importantes nesse processo do que chamamos resistência ao colonialismo. A sempre difícil penetração nesses espaços, aliada ao fim do tráfico de escravos no continente, trouxeram mudanças na perspectiva bélica e gestou algumas das dicotomias existentes ainda hoje entre Europa e África. Nesse sentido, o Islã aparecia tanto como resistência quanto como um fator de unidade fundamental para os povos da África subsaariana (BITTENCOURT, 2003, p. 76).

\begin{abstract}
A nova expansão islâmica associada ao desdobramento das redes comerciais que atravessavam o Saara, conectando-se aos postos de troca no oceano Atlântico, e ao crescimento do comércio de armas alteraram a paisagem política e militar da região, possibilitando reações de maior envergadura dos africanos à presença europeia. (BITTENCOURT, 2003, p. 76)
\end{abstract}

Impossível iniciarmos a explanação sem levar em consideração a escravidão e o tráfico como partes preponderantes nessa equação, sobretudo, porque eram bastante presentes em grande parte dos Estados africanos. Por conta da inexistência da noção de propriedade privada, era a presença de escravos que media o poderio desses Estados e as mudanças no tráfico geraram um desequilíbrio econômico e político dentro dos espaços africanos, prejudicando fortemente sua hegemonia (FERRO, 2008, p. 227).

Nesse momento selecionamos três representantes dos movimentos de contestação colonial e a escolha se deu por meio da constatação dos papéis de protagonismo de Samory Touré, Omar Tall e Mohamed Ahmed.

O líder muçulmano Samory Touré foi um dos primeiros representantes da resistência no Sudão à penetração francesa, sendo o responsável pelo controle de um vasto império de expressão messiânica no Mali entre 1880 e 1890. De alguma maneira, a sua ascensão foi propiciada pelo 
movimento de "modernização" do islã e dos ensinamentos do alcorão, desenvolvendo uma expansão do ideal militar dentro das ordens religiosas. O uso dos cavalos e a ideia da luta militar associada ao religioso foi algo bastante presente na sua organização das sociedades africanas da sua época (BITTENCOURT, 2003, p. 76).

Graças a essa militarização e ao controle dos gêneros alimentares, Touré pôde realizar uma forte oposição às tropas francesas em todo território do Sudão Francês. A sua hostilidade contra a presença francesa foi perpetuada na historiografia europeia que o representava como alguém desprovido de racionalidade. Seu caráter messiânico aliado à sua estratégia de isolar as tropas francesas gerou uma hostilidade em relação aos territórios vizinhos, que tiveram suas terras queimadas do mesmo modo (BITTENCOURT, 2003, p. 77).

Por outro lado, a organização de Touré contou com a participação de artesãos, pequenos comerciantes, funcionários, marabusii e líderes religiosos desse Estado que se associaram ao

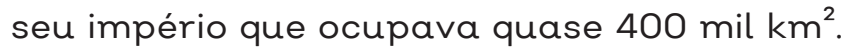
Tendo provocado uma significativa mudança nas sociedades africanas de seu tempo, ele trouxe uma forma de tributação que atingiria um campo político bastante diferente para as estruturas de sua época (FERRO, 2008, p. 228).

Como exalta Marc Ferro (2008, p.228), a historiografia francesa tratou Samory Touré como um tirano de caráter messiânico que ocupou um papel de extremista religioso para direcionar uma multidão contra a colonização francesa. Interessante notar que essa mesma interpretação em torno das lideranças africanas trabalhou por muitos anos para descrever a África sem levar em conta a formação dos estados, pois sem esses estados não se têm história.

Desse ponto de vista, o Estado que Samory foi capaz de construir no século XIX no Sudão é exemplar, sendo o resultado da associação entre um indivíduo excepcional e um grupo social, os dyulas, comerciantes, cuja expansão está ligada a uma renovação do Islã. (FERRO, 2008, p. 228)
"No ano de 1881, o império mandinga erigido sob sua liderança englobava parte do território dos atuais países da Guiné, Mali, Serra Leoa e Libéria, numa área territorial que comportava uma população que beirava um milhão de pessoas" (MACEDO, 2015, p. 129).

O fator de resistência nas articulações de Samory Touré foi bastante contundente, demonstrando capacidade de alianças e conhecimento dos territórios de tal maneira que gerou incômodo tanto para franceses quanto para os ingleses em fins do século XIX. Apesar de sua derrota no início do século $X X$, os historiadores modernos apontam que Touré foi o maior representante de um enorme ciclo de derrotas do império mandinga sob a França (GUEYE; BOAHEN, 2011, p. 147).

Outro importante personagem na liderança africana desse período foi Omar Tall, responsável pela nova ordenação político-religiosa dentro da África Ocidental. Na década de 1860, alguns anos antes de Touré, Omar Tall tentava reorganizar parte da Guiné e do Mali em função da instabilidade ocasionada pela proibição do tráfico nessas regiões.

Passando por cima das divergências étnicas, esse líder religioso tuculeur consegue promover uma união nunca antes vista nesses territórios, tendo o islamismo mais uma vez um papel preponderante nessas uniões. Apesar das dificuldades econômicas, o papel de liderança de Tall foi importante para frear a aproximação francesa no período.

Especialmente o Mali foi um local de grande penetração das noções de resistência de Tall, visto que devido à grande diversidade étnica de sua composição religiosa também foi grande exemplo da penetração do islã e de sua adaptação às realidades tradicionais dos povos. As línguas e culturas acabaram se amalgamando em função da oposição aos ideais colonizadores exógenos (WALDMAN; SERRANO, 2010, p. 312-3).

De uma maneira ou de outra, o estudo da vida de alguns desses líderes religiosos demonstra a existência de vozes dissonantes dentro dessas 
sociedades africanas no auge das investidas colonizadoras da era contemporânea. O fim de Omar Tall não representou o findar da contestação colonial, mas o quanto as diferenças tecnológicas se acentuaram em um contexto de decadência econômica africana.

"Sua morte aos 65 anos, em 1864, agravaria as inúmeras contradições no interior de seu império, que não consegue consolidar-se, incapaz de reforçar a ideia de integração das populações submetidas" (KI-ZERBO, 1972, p. 22-26).

O terceiro ícone dos processos de resistência escolhido é Muhammad Ahmad e falar de sua ascensão como líder no Sudão não é tarefa nada fácil, contudo, ele foi precursor na divulgação da resistência quando propagou a noção de luta contra as ideias estrangeiras. Em 1881, foi proclamado mahdi, liderando a revolta Mahdista na mesma região, em oposição ao contato britânico e suas imposições políticas e econômicas. O estado mahdista ainda merece atenção nessa mesma perspectiva, pois apropriou-se das noções do islamismo dando um sentido de unidade ao povo no Sudão (SANTOS, 2013, p. 66-7).

Nascido por volta do ano de 1834, o menino mahdi teria começado desde cedo seus estudos no islamismo, destacando-se por sua grande inteligência nos ensinos ligados ao sufismo. Foi considerado o "mahdi", que queria dizer "o guia", alguém capaz de representar diretamente Alá, cuja responsabilidade principal era criar um "reino de justiça" no mundo (MACEDO, 2015, p. 131).

Nos anos de 1870, Muhammad Ahmad funda sua própria confraria e, de acordo com Dujarric e Bermann, começa a fazer suas viagens proselitistas pelo norte do Sudão, quando então passa a se identificar com a insatisfação de importantes santos sufis da Qadiriyya e da Shadhiliyya com o domínio otomano-egípcio. (SANTOS, 2013, p. 67)

A resistência do Mahdi passou tanto pelo aspecto da oposição ao colonizador, quanto pela negação aos egípcios, demonstrando a força do Estado de inspiração político-religiosa que foi o Mahdismo. O processo de construção da figura do mahdi ainda está em consolidação no nosso país e é possivel dizer que um dos trabalhos mais aprofundados sobre ele em uma perspectiva histórica é a obra da professora Dra. Patrícia Teixeira Santos, intitulada Fé, Guerra e Escravidão - Uma História da Conquista Colonial do Sudão (1881-1898), 2013.IV

Vale notar que como todo movimento tido como messiânico, ele deixou uma tradição que ressignificava a experiência religiosa do islã e fornecia legitimidade em relação aos movimentos de independência surgidos décadas após. A própria figura do mahdi e sua construção na qualidade de líder messiânico trouxe uma (re)valorização dos fiéis dentro do islamismo. Em função do seu "carisma", parte da historiografia tentou representá-lo negativamente como uma figura radical que somente foi capaz de se articular por conta de uma multidão "perdida e desgarrada", como aconteceu diversas vezes nos relatos europeus acerca dessas lideranças da resistência africana (SANTOS, 2013 p. 164).

"Em 1881 suas forças iniciam uma expansão mais ousada ao sul. Com sua morte em 1885, as forças de desagregação se fariam sentir. Uma nova derrota deixaria 11 mil mortos madistas. Em 1899 os ingleses já controlavam a situação" (BITTENCOURT, 2003, p. 9 apud OLIVER, 1994, p. 203-206). De alguma maneira ele foi derrotado, mas suas representações deram à História da África um grande manancial de fontes para o estudo das resistências via o estudo do islã no continente africano.

O Mahdi conseguiu inaugurar um campo de lutas atreladas ao campo religioso e, apesar de sua derrota, o Estado Mahdista representou durante algum tempo sua proposta de união por meio do islã. A ausência de sua personalidade gerou claramente um vazio de poder no qual a conjuntura política não conseguiu mais se manter no Sudão.

\section{Considerações Finais}

Este artigo realizou um breve apanhado de alguns pontos fundamentais para as novas pesquisas e reflexões acerca dos estudos 
africanos no Brasil, enfocando a colonização e sua consequente resposta na virada do século XIX e XX. Por meio da compreensão das abordagens envolvendo África e Europa compreende- se também as etapas do processo de domínio colonial até a instalação das estruturas coloniais propriamente ditas. Buscou-se demonstrar todo o processo que passa pelo contato colonial, mas objetiva demonstrar alguns dos líderes que protagonizaram rejeição ao mecanismo colonial e protagonistas importantes de uma inovadora historiografia.

Esses líderes são de extrema importância para o estudo dos processos de resistência nos estudos africanos, sendo todos eles grandes exemplos de como o Estado na África tinha um poder de organização político-religioso que não deixava nada a desejar aos seus vizinhos europeus. Como enfatizou Marc Ferro (2013, p. 229):

Assim, ali onde existiram verdadeiros Estados - que a tradição histórica europeia ignorou -, a resistência militar foi dizimada, mas nem por isso a destruição desses Estados liquidou com a ideia de independência, que permaneceu viva, tanto na África Ocidental como em Madagáscar e no Quênia; a contrapartida, se podemos dizer assim, é que a lenda popular ou erudita transformou esses chefes derrotados em verdadeiros heróis, [...]

Considerar as resistências africanas contemporâneas como respostas legítimas à violência colonial é ainda romper com a História dos vencidos, em uma perspectiva de contato colonial, subtraindo a falsa ideia de aceitação dos processos de violência e dominação perpetrados pelos colonizadores europeus. Ainda se faz necessária a retomada desses processos levando em consideração as imposições coloniais em relação ao surgimento das estruturas de unidade (e solidariedade) no seio de inúmeras sociedades africanas. O estudo da "resistência", além de uma interpretação diversa da historiografia tradicional, foi capaz de devolver aos sujeitos o protagonismo de suas próprias narrativas. Como diria Frantz Fanon, na obra de Saïd Boumama:
Cabe destacar [...] o papel que desempenha no fenômeno de maturação, a história da resistência nacional até a conquista. Os povos colonizados são sempre aqueles que dirigiram a resistência nacional à invasão. Béhazin, Soundiata, Samory, Abdelkader revivem com uma particular intensidade no período que precede a ação. É prova de que o povo está se preparando a interromper o tempo morto pelo colonialismo para fazer História. (FANON apud BOUMAMA, 2017, p. 27 tradução livre do autor)

\section{Referências}

ASAD, T. Genealogies of Religion: Discipline and Seasons of Power in Christianity and Islam. Baltimore: The Johns Hopkins University Press, 1993.

BITTENCOURT, M. Partilha, resistência e colonialismo. Introdução à história da África e da cultura afro-brasileira. Rio de Janeiro: CEAA-Ucam - CCBB, 2003.

BOUAMAMA, S. Figures de la revolution africaine. De Kenyatta à Sankara. Paris: La Découverte, 2017.

BLAKE, J. The truth About Colonies, 1931: Art Indigène in Service of Revolution. Oxford Art Journal, vol. 25, n.1, 2002, p.47.

BRUNSCHWIG, H. A partilha da África Negra. São Paulo: Editora Perspectiva, 2006.

CURTIN, P. Tendências recentes das pesquisas históricas africanas e contribuições à história em geral. In: KI-ZERBO, J. (Org.). História geral da África, vol. I. Metodologia e Pré-História da África. Brasília: UNESCO, 2010.

DAVIDSON, B. The Search for a New Society. Baltimore/ Maryland: Pinguin books; Pinguin African Library, 1967.

FERRO, M. A colonização explicada a todos. São Paulo: Editora Unesp, 2017.

FERRO, M. História das colonizações: das conquistas às independências - século XIII a XX. São Paulo: Cia das Letras, 2008. 
GUEYE, M'Baye; BOAHEN, A. A. Capítulo 6 - Iniciativas e Resistências africanas na África Ocidental (1880-1935). História geral da África, vol. VII. África sob dominação colonial (1880-1914). Brasília: UNESCO, 2011.

ILIFFE, J. Les Africains: Histoire d'un continent. Paris: Flammarion, 2007.

KHAPOYA, V. A experiência africana. Petrópolis: Editora Vozes, 2008.

KI-ZERBO, J. História da África Negra. Volume 1. Lisboa: Edições Europa-América, 2009.

História da África Negra. Volume 2. Lisboa: Edições Europa-América, 1972.

KIERNAN, V. G. Imperialism and its contradictions. Nova Iorque: Routledge, 1995.

MACEDO, J. R. História da África. São Paulo: Editora Contexto, 2015.

MUDIMBE, V. Y. Invenção de África. Gnose, Filosofia e a Ordem do Conhecimento. Mangualde: Edições Pedago, 2013.

OLIVER, R. A experiência africana: da pré-história aos dias atuais. Rio de Janeiro: Jorge Zahar, 1994.

QUADRAT, S. V.; ROLLEMBERG, D. A construção nacional dos regimes autoritários. África e Ásia. Rio de Janeiro: Editora Civilização Brasileira, 2011. RANGER, T.; HOBSBAWM, E. A invenção das tradições. São Paulo: Editora Paz e Terra, 2008.
Cap. 3 - Iniciativas e resistência africanas em face da partilha e da conquista. In: BOAHEN, A. A. (org.). História geral da África. vol. VII. África Sob Dominação Colonial (1880-1935). Brasília: UNESCO, 2011.

SAID, E. Cultura e imperialismo. São Paulo: Companhia das Letras, 2005.

Reflexões sobre o exílio e outros ensaios. São Paulo: Companhia das Letras, 2003. SANTOS, P. T. Fé, guerra e escravidão: uma história da conquista colonial do Sudão (1881-1898). São Paulo: Editora FAP-UNIFESP, 2013.

SERRANO, C.; WALDMAN, Mo. Memória D’África: a temática africana em sala de aula. 3. ed. São Paulo: Cortez Editora, 2010.

THORNTON, J. A África e os africanos na formação do mundo atlântico (1400-1800). 3.ed. Rio de Janeiro: Capus/Elsevier, 2004.

UZOIGWE, G. N. Cap. 2 - Partilha europeia e conquista da África: apanhado geral. In: BOAHEN, A. A. (org.). História geral da África. vol. VII. África sob dominação colonial (18801935). Brasília: UNESCO, 2011.

VERGÈS, F. L'Outre-Mer: une survivance de l'utopie colonial républicaine?. In: BLANCHARD, P.; BANCEL, N.; LEMAIRE, S. (dir). La Fracture Coloniale. La société française au prisme de l'héritage colonial. Paris: La Découverte, 2006. 